\title{
PELATIHAN PENGOLAHAN LIMBAH TOILET MENGGUNAKAN FORMULA MIKROBA DI PERUMAHAN TENGGILIS SURABAYA
}

\author{
TOILET WASTE TREATMENT TRAINING USING MICROBIC FORMULA IN TENGGILIS SURABAYA \\ HOUSING
}

\section{Fatimah}

Fakultas Sains dan Teknologi

Tini Surtiningsih

Fakultas Sains dan Teknologi

Agus Supriyanto

Fakultas Sains dan Teknologi

Nima'tuzahroh

Fakultas Sains dan Teknologi

\section{Salamun}

Fakultas Sains dan Teknologi

Tri Nurhariyati

Fakultas Sains dan Teknologi

\begin{abstract}
ABSTRAK
Penyumbatan septic tank merupakan salah satu permasalahan di masyarakat terkait dengan buangan limbah toilet yang dihasilkan. Penggunaan pembersih toilet yang berbahan sintetik yang tidak ramah lingkungan merupakan salah satu faktor yang dapat menghambat proses penguraian limbah organik. Keberadaan bahan pembunuh mikroba dalam bahan-bahan pembersih toilet yang ikut masuk ke dalam septik tank justru akan menghambat pertumbuhan mikroba esensial yang berperan dalam kesempurnaan proses dekomposisi. Kurangnya pemahaman masyarakat terkait dengan proses mikroba dalam pengolahan limbah toilet merupakan salah satu faktor ketidakmampuan masyarakat dalam mengatasi permasalahan tersebut. Pengabdian masyarakat ini bertujuan untuk mensosialisasikan informasi terkait proses pengolahan limbah organik, peran mikroba dalam pengolahan limbah toilet, cara membuat formula mikroba yang berperan dalam pengolahan limbah toilet, serta upaya meningkatkan kreativitas masyarakat untuk mengolah limbahnya sendiri guna meningkatkan sanitasi lingkungan dan meningkatkan kesejahteraan masyarakat. Hasil pelatihan menunjukkan bahwa rerata nilai pretest dan post test kader kelurahan Tenggilis Surabaya mengalami peningkatan nilai yang cukup signifikan dengan rerata nilai dari 37,78 (pretest) menjadi 62,22 (post test). Kader pengolahan limbah toilet telah mampu membuat produk biotoilet yang dapat dimanfaatkan untuk mengolah limbat toilet di rumah masing-masing. Informasi dan wawasan yang mereka terima dapat di teruskan kepada komunitas asal masing-masing kader.
\end{abstract}

Kata kunci: Formula mikroba, kader pengolahan limbah toilet, limbah organik, pelatihan

\section{ABSTRACT}

Blockage of septic tanks is one of the problems in the community related to the discharge of toilet waste produced. The use of synthetic toilet cleaners that are not environmentally friendly is one of the factors that can inhibit the process of decomposing organic waste. The existence of microbial killer ingredients in toilet cleaning materials that come into the septic tank will actually inhibit the growth of essential microbes that play a role in the perfection of the decomposition process. Lack of understanding of the community related to microbial 
processes in the processing of toilet waste is one of the factors inability of the community to overcome these problems. This community service aims to disseminate information related to the processing of organic waste, the role of microbes in the processing of toilet waste, how to make microbial formulas that play a role in the processing of toilet waste, as well as efforts to increase the creativity of the community to process their own waste to improve environmental sanitation and improve community welfare. The results of the training showed that the average pretest and post test scores of the cadres of Tenggilis Surabaya village experienced a significant increase in value with a mean value of 37.78 (pretest) to 62.22 (post-test). Toilet waste processing cadres have been able to make biotoilet products that can be used to process limbat toilets in their homes. The information and insights they receive can be passed on to the community from each cadre.

Keywords: microbial formula, toilet waste processing cadre, organic waste, training

\section{PENDAHULUAN}

\section{Latar Belakang}

Produksi limbah organik di lingkungan terus meningkat seiring dengan peningkatan jumlah penduduk. Limbah domestik dari sumber toilet di setiap rumah tangga merupakan salah satu bentuk dari limbah organik yang ada di lingkungan. Selama ini, limbah tersebut cenderung ditampung dalam septic tank dan ada juga yang dibuang di perairan.

Tersumbatnya septic tank merupakan salah satu permasalahan di masyarakat terkait dengan buangan limbah toilet yang dihasilkan. Masa pengurasan septic tank yang terlalu cepat juga sering dijumpai akhir-akhir ini. Penggunaan pembersih toilet yang berbahan sintetik yang tidak ramah lingkungan juga merupakan salah satu faktor yang dapat menghambat proses penguraian limbah organik. Keberadaan bahan pembunuh mikroba dalam bahan pembersih toilet yang ikut masuk ke dalam septic tank justru akan menghambat pertumbuhan mikroba esensial yang berperan dalam kesempurnaan proses dekomposisi. Kurangnya pemahaman masyarakat terkait dengan proses mikroba dalam pengolahan limbah toilet merupakan salah satu faktor ketidakmampuan masyarakat dalam mengatasi permasalahan tersebut.

Semakin sering frekuensi pengurasan limbah toilet mengakibatkan semakin banyak limbah tersebut harus dibuang di tempat penampungan limbah umum dan menambah beban pengolahan limbah pemerintah kota. Biaya yang harus dikeluarkan oleh masing-masing keluarga juga semakin bertambah dengan seringnya melakukan pengurasan.

Bahan organik yang ada dalam limbah toilet secara alamiah dapat diuraikan oleh mikroba dekomposer. Pemberian formulasi mikroba pengurai dalam saluran pembuangan merupakan salah satu upaya dalam mengatasi tersumbatnya toilet. Mikroorganisme yang dapat mengatasi tersumbatnya toilet dikenal dengan mikroba biotoilet.

Salah satu penelitian yang dikembangkan di Laboratorium Mikrobiologi, Fakultas Sains dan Teknologi, Universitas Airlangga adalah membuat formula mikroba potensial yang dapat diaplikasikan untuk berbagai kegunaan, antara lain: pengolahan limbah organik, perikanan, pertanian dan perlindungan lingkungan. Formula mikroba biotoilet merupakan salah satu produk mikroba dari Laboratorium Mikrobiologi, Fakultas Sains dan Teknologi, Universitas
Airlangga yang dikhususkan untuk penguraian limbah toilet. Implementasi produk biotoilet di masyarakat akan semakin meningkatkan peran perguruan tinggi (Universitas Airlangga) dalam mengatasi permasalahan lingkungan.

Sosialisasi informasi terkait dengan proses pengolahan limbah organik, peran mikroba dalam pengolahan limbah toilet, cara membuat formula mikroba yang berperan dalam pengolahan limbah toilet, serta upaya meningkatkan kreativitas masyarakat untuk mengolah limbah nya sendiri merupakan agenda pemerintah yang sangat penting untuk dilakukan guna meningkatkan sanitasi lingkungan dan meningkatkan kesejahteraan masyarakat.

\section{Rumusan Masalah}

Rumusan masalah yang diajukan pada kegiatan ini adalah sebagai berikut.

1. Masyarakat memerlukan informasi terkait proses penguraian limbah secara alamiah dan peran mikroba dalam pengolahan limbah toilet

2. Masyarakat belum sepenuhnya memahami cara mengatasi permasalahan limbah toilet

3. Masyarakat belum memahami cara membuat formula mikroba biotoilet

4. Masyarakat belum banyak yang berperan aktif dalam menjaga kebersihan, kesehatan dan permasalahan di lingkungan

\section{Tinjauan Pustaka}

Limbah merupakan buangan atau sesuatu yang tidak terpakai berbentuk cair, gas dan padat. Salah satunya adalah limbah rumah tangga yang tidak dapat terlepas dari kegiatan manusia setiap harinya, mulai dari limbah dapur hingga limbah aktivitas anggota keluarga, seperti mencuci, mandi, buang air besar, buang air kecil, dan sebagainya. Produksi limbah rumah tangga yang tidak pernah berhenti ini seringkali tidak disadari, sehingga masyarakat membuangnya begitu saja tanpa memperhatikan dampaknya. Limbah padat dapat dikumpulkan dalam bak sampah untuk kemudian dibuang ke pembuangan sampah sementara (TPS). Sedangkan, limbah cair umumnya dibiarkan mengalir melalui selokan dan akhirnya meresap ke dalam tanah, dan mencemari tanah dan 
air dalam tanah. Seperti halnya limbah cair yang bersumber dari toilet di setiap rumah tangga, selama ini limbah tersebut cenderung ditampung dalam septic tank dan ada juga yang dibuang di perairan. Dampak dari aktivitas tersebut adalah terjadinya penurunan kualitas air dan menimbulkan masalah kekurangan air yang berkualitas, penyakit menular, dan lainlain (Indra, 2014).

Limbah tersebut dapat bersifat organik maupun anorganik (Setiawan, 2013). Berikut ini merupakan perbedaan antara keduanya (Indra, 2014), yakni:

a. Limbah Organik Segala macam limbah yang mengandung unsur karbon (C). Contohnya, limbah dari makhluk hidup seperti sisa makanan, sisa sayuran, air seni, kotoran manusia dan hewan. Bahan organik yang ada dalam limbah toilet secara alamiah dapat diuraikan oleh mikroba dekomposer.

b. Limbah Anorganik Limbah yang tidak dapat atau sulit terurai. Limbah jenis ini tidak mengandung unsur karbon, seperti logam (misalnya besi dari mobil bekas atau perkakas dan alumunium dari kaleng bekas atau peralatan rumah tangga) dan kaca.

Bahan organik yang ada dalam limbah toilet secara alamiah dapat diuraikan oleh mikroba dekomposer. Pemberian formulasi mikroba pengurai dalam saluran pembuangan merupakan salah satu upaya dalam mengatasi tersumbatnya toilet. Mikroorganisme yang dapat mengatasi tersumbatnya toilet dikenal dengan mikroba biotoilet. Formula mikroba biotoilet pada kegiatan ini mengandung 8 jenis biakan murni yaitu Cellulomonas, Cytophaga, Cellvibrio, Bacillus megaterium, Bacillus subtilis, Bacillus licheniformis, Lactobacillus plantarum, dan Saccharomyces cerevisiae.

Formula mikroba biotoilet ini apabila diaplikasikan pada toilet maka efek yang terlihat adalah limbah yang berbentuk padat akan diurai menjadi cairan (tidak mampet), jumlah air berkurang menjadi $60-80 \%$ dari volume total dari isi septic tank, karena proses oksidasi (menguap/tidak perlu sedot) dan gas yang keluar menjadi lebih banyak tetapi tidak berbau karena bukan $\mathrm{NH}_{3}$ (amoniak) dan $\mathrm{H}_{2} \mathrm{~S}$ (hidrogen sulfida), kedua gas tersebut baunya busuk dan menyengat. Pertumbuhan bakteri merugikan dalam WC juga dapat ditekan, dengan demikian rembesan septic tank tidak lagi membahayakan kesehatan masyarakat (Setiawan, 2013).

\section{Tujuan dan Manfaat}

Tujuan kegiatan pengabdian masyarakat ini adalah sebagai berikut:

a. Memberikan informasi ilmiah kepada masyarakat tentang proses mikroba dalam pengolahan limbah toilet

b. Meningkatkan kemampuan masyarakat dalam mengatasi permasalahan limbah toilet c. Memberikan pelatihan cara membuat formula mikroba biotoilet

d. Meningkatkan peran serta masyarakat dalam kebersihan, kesehatan dan mengatasi permasalahan yang ada di lingkungannya

Kegiatan ini memberikan manfaat sebagai berikut:

a. Masyarakat dapat mengatasi sendiri permasalahan yang timbul terkait dengan limbah toilet

b. Mengurangi biaya operasional yang dikeluarkan oleh masyarakat dalam mengolah limbah organik

c. Masyarakat dapat berperan mengurangi beban limbah organik di pemukiman

d. Memberikan bekal kepada masyarakat untuk mengembangkan starter mikroba biotoilet yang dapat digunakan untuk pengolahan limbah toilet

\section{METODE PENGABDIAN}

Metode pengabdian kepada masyarakat dilakukan dengan beberapa tahapan yang dijelaskan pada sub bab 1 hingga 3 .

\section{Waktu dan Tempat Pengabdian}

Waktu pelaksanaan Program Pengabdian Masyarakat dilaksanakan pada bulan Agustus 2017. Tempat pelaksanaan pengabdian di Pendopo Kelurahan Tenggilis Mejoyo, Kecamatan Tenggilis, Surabaya.

\section{Metode dan Rancangan Pengabdian}

Pelaksanaan kegiatan ini dilakukan dengan beberapa langkah, yaitu: perencanaan, tindakan, dan evaluasi. Kegiatan-kegiatan atau aktivitas-aktivitas dari masing-masing tahapan adalah sebagai berikut:

a. Perencanaan

Kegiatan-kegiatan yang dilakukan pada tahap perencanaan adalah:

1. Sosialisasi program pengabdian masyarakat kepada warga perumahan Tenggilis Surabaya

2. Persiapan pembuatan starter atau bibit bakteri untuk pembuatan formula biotoilet

b. Tindakan

Tindakan dalam kegiatan ini berupa implementasi program pelatihan. Kegiatan-kegiatan yang dilakukan dalam implementasi program adalah:

1. Peningkatan pengetahuan dalam mengatasi permasalahan limbah toilet. Metode yang ditawarkan adalah ceramah, tanya jawab, dan diskusi. Pretest dan post test dilakukan untuk mengukur pemahaman peserta terhadap materi yang diberikan. 
2. Pelaksanaan pelatihan dilakukan baik secara teori maupun praktek dengan narasumber ahli, yaitu dari tim pengabdian kepada masyarakat, dosen laboratorium Mikrobiologi, Departemen Biologi, FST Universitas Airlangga. Materi yang diberikan adalah pelatihan teori dan praktek pembuatan biotoilet. Metode pelatihan yang digunakan adalah diskusi dan latihan pembuatan dan perbanyakan formula biotoilet. Untuk mendukung keberhasilan pelatihan pembuatan biotoilet diberikan bantuan sekitar 50 L starter mikroba biotoilet dan 3 L molase sebagai medium pertumbuhannya untuk selanjutnya dapat diperbanyak secara mandiri oleh warga perumahan Tenggilis Surabaya.

c. Evaluasi

Praktek pembuatan dan perbanyakan formula dilaksanakan setelah pemberian materi. Peserta pelatihan adalah ibuibu kader lingkungan, mereka sangat antusias untuk mencoba membuat sendiri dan juga menyampaikan teknik pembuatan formula mikroba biotoilet kepada komunitas mereka masing-masing serta memperbanyak produk tersebut.

\section{Peserta Sosialisasi dan Kader}

Peserta pelatihan berasal dari warga perumahan Tenggilis Surabaya, yang diwakili oleh ibu-ibu kader lingkungan sejumlah 18 orang.

\section{HASIL DAN PEMBAHASAN}

Pengabdian ini dilakukan dengan terlebih dahulu mengadakan diskusi antara tim pengabdian dengan kelompok mitra pengabdian. Tujuan dari dilaksanakannya diskusi ini adalah untuk mencari dan merumuskan permasalahan sebenarnya yang dialami oleh kelompok mitra pengabdian.
Tindak lanjut dari diskusi adalah memotivasi mitra dalam pemberdayaan komunitasnya agar mampu lebih produktif, meningkatkan pengetahuan mitra mengenai masalah pengolahan limbah toilet yang lebih ramah terhadap lingkungan dengan biaya yang lebih murah

Lokasi pelatihan pengolahan limbah toilet ini dilakukan di Balai Kelurahan Tenggilis Mejoyo Surabaya yang bersamaan dengan kegiatan Kuliah Kerja Nyata Belajar Bersama Masyarakat (KKN-BBM) Universitas Airlangga tahun 2017. Pembinaan untuk pelatihan pengolahan limbah toilet ini dilakukan dengan pemberian materi teori mengenai pengetahuan tentang limbah toilet dan cara pengolahannya menggunakan berbagai mikroba potensial pendegradasi limbah toilet (Gambar 1a). Pelaksanaan kegiatan di evaluasi melalui pemberian pretest dan post test bagi peserta pelatihan (Gambar 1b). Evaluasi pretest dan post test menunjukkan bahwa terdapat peningkatan wawasan dan pengetahuan mitra terkait limbah toilet dan pengolahannya. Kegiatan ini bertujuan untuk memberikan pengetahuan pengolahan limbah toilet yang lebih ramah lingkungan dengan biaya lebih murah.

Peserta pelatihan yang terdiri atas ibu-ibu kader mengalami peningkatan pemahaman tentang pembuatan biotoilet. Hal ini ditunjukkan oleh hasil evaluasi rerata nilai pre dan post tes setelah mendapat pengetahuan mengenai pengolahan limbah toilet. Pelatihan ini berfungsi untuk mempermudah pengolahan limbah toilet skala rumah warga Tenggilis Surabaya menggunakan formula mikroba potensial yang lebih ramah lingkungan berupa produk biotoilet. Selanjutnya kader akan menyampaikan informasi dan mengatur kinerja sesuai dengan pelatihan kepada warga sekitar lainnya.

Berdasarkan hasil pretest (Gambar 2), diketahui sebanyak $70 \%$ peserta belum mengenal formula mikroba biotoilet, $61 \%$ belum mengetahui pembuatan formula mikroba biotoilet, dan $44 \%$ belum mengetahui pemanfaatan formula mikroba biotoilet.

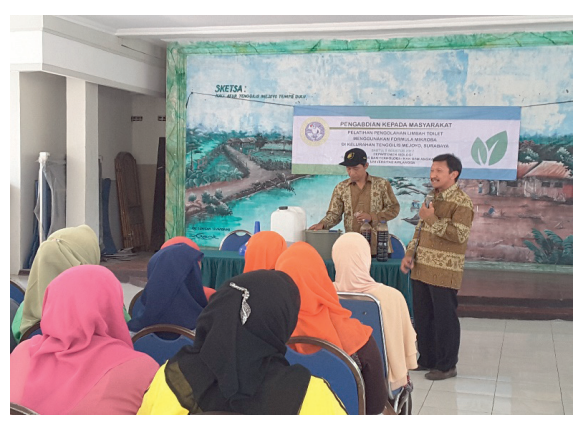

a

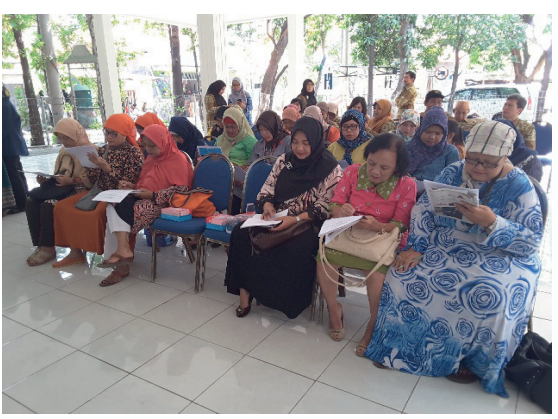

b

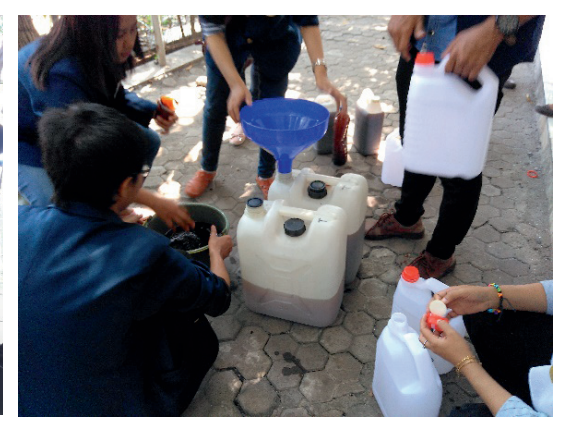

c

Gambar 1. Pelatihan pengolahan limbah toilet. a. Pemberian materi oleh tim pengabdian masyarakat, b. Peserta mengerjakan pretest, $\mathbf{C}$ Praktek pembuatan biotoilet bersama mahasiswa KKNBBM. 


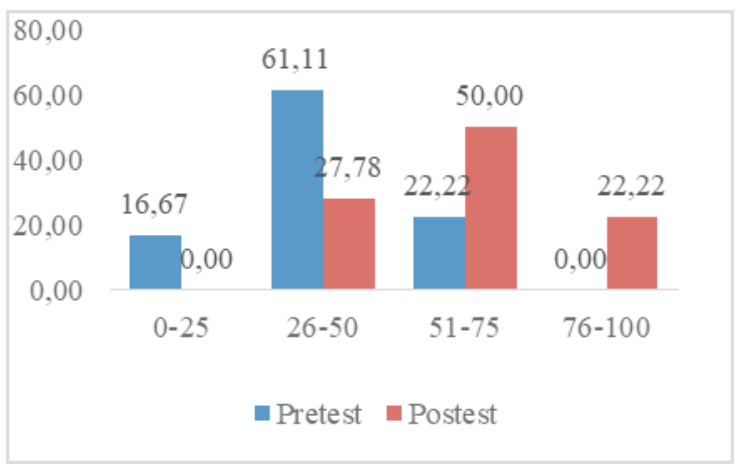

Gambar 2. Hasil rerata pretest dan post test peserta pelatihan pengolahan limbah toilet.

Setelah pelaksanaan ceramah, praktek, dan diskusi, kemudian dilakukan post test, pada post test didapatkan hasil dengan persentase sebanyak $100 \%$ peserta mengenal formula mikroba biotoilet, mengetahui pembuatan formula mikroba biotoilet, dan mengetahui pemanfaatan formula mikroba biotoilet. Hasil rerata nilai pretest dan post test kader Kelurahan Tenggilis Surabaya mengalami peningkatan nilai yang cukup baik dengan rerata nilai dari 37,78 (pretest) menjadi 62,22 (post test).

\section{SIMPULAN, SARAN, DAN REKOMENDASI}

Simpulan dari program pengabdian masyarakat ini adalah proses sosialisasi mampu meningkatkan wawasan dan kemampuan masyarakat tentang pengolahan limbah toilet dengan memanfaatkan mikroba potensial dan cara pembuatan formula mikroba pendegradasi limbah toilet (biotoilet).

Berdasarkan hasil evaluasi dan pengamatan pada saat pelaksanaan pengabdian, maka sebaiknya materi ini dapat diberikan kepada masyarakat secara kontinu dan berkesinambungan di tempat-tempat lain.

\section{UCAPAN TERIMA KASIH}

Kegiatan ini dibiayai oleh Bantuan Pendanaan Perguruan Tinggi Negeri (BPPTNBH) Universitas Airlangga sesuai dengan Surat Keputusan Rektor Universitas Airlangga Nomor : 1127/UN3/2017, tanggal 11 Agustus 2017. Terima kasih diucapkan kepada Lurah dan warga Kelurahan Tenggilis Mejoyo Surabaya atas kerja samanya dalam pelaksanaan kegiatan ini.

\section{DAFTAR PUSTAKA}

Indra, Ary. 2014. Limbah Rumah Tangga. https://www.scribd. com/document/223584927/Limbah-Rumah-Tanggapdf.

Setiawan, Bambang, 2013. Product Knowledge SW Toilet (Bakteri Pengurai Limbah). http://sw-group.blogspot. co.id/2013/10/product-knowledge-sw-toilet-bakteri. html. 